\title{
Ice velocity mapping of Ross Ice Shelf, Antarctica by matching surface undulations measured by ICESat laser altimetry
}

\author{
Choon-Ki Lee ${ }^{\text {a,* }}$, Ki-Weon Seo ${ }^{\text {a }}$, Shin-Chan Han ${ }^{\text {b,c }}$, Jaehyung Yu ${ }^{\text {d }}$, Ted A. Scambos ${ }^{\text {e }}$ \\ a Division of Polar Earth-System Sciences, Korea Polar Research Institute, Incheon, Republic of Korea \\ b Planetary Geodynamics Laboratory, Code 698, NASA Goddard Space Flight Center, Greenbelt, MD, USA \\ c Joint Center for Earth Systems Technology, University of Maryland at Baltimore County, Baltimore, MD, USA \\ d Department of Geology and Earth Environmental Sciences, Chungnam National University, Daejeon, Republic of Korea \\ e National Snow and Ice Data Center, CIRES, University of Colorado, Boulder, CO, USA
}

\section{A R T I C L E I N F O}

\section{Article history:}

Received 22 November 2011

Received in revised form 17 May 2012

Accepted 19 May 2012

Available online 13 June 2012

\section{Keywords:}

Ice velocity

Laser altimetry

Ross Ice Shelf

\begin{abstract}
A B S T R A C T
We present a novel method for estimating the surface horizontal velocity on ice shelves using laser altimetry data from the Ice Cloud and land Elevation Satellite (ICESat; 2003-2009). The method matches undulations measured at crossover points between successive campaigns. Elevation measurements are first relocated into a time-varying (moving) coordinate system using an initial velocity (e.g., from VELMAP), and then crossover height differences are minimized with an adjustment vector. Errors in geolocation of the ICESat tracks result in some error in the adjustment vectors, but these are small relative to the velocity adjustment for fast-moving ice shelves. We use the algorithm to estimate changes in the ice velocity of Ross Ice Shelf between an earlier mapping (from VELMAP) and the ICESat period. The new velocity field is compared with velocities from in situ measurements and satellite radar interferometry. The slowdown of $98 \pm 34 \mathrm{~m} \mathrm{yr}^{-1}$ $(\sim 23 \%)$ is observed in the ice shelf downstream of Whillans Ice Stream, and the deceleration rate is $3.1 \pm$ $1.1 \mathrm{~m} \mathrm{yr}^{-2}$ during last three decades. The method can be expanded to the simultaneous mapping of ice horizontal velocity, ice thickness change, and surface deformation for Antarctic ice shelves as well as a more accurate mapping using future ICESat-2 measurements.
\end{abstract}

(c) 2012 Elsevier Inc. All rights reserved.

\section{Introduction}

The ice velocity of an ice shelf is a key parameter for understanding its dynamics and its interaction with the inland ice sheet. A changing ice shelf velocity field provides insight into dynamical changes of the inflowing grounded ice, or changes in basal melt or stress balance within the shelf. Many methods exist for mapping ice shelf velocity (e.g., interferometric SAR (InSAR) or InSAR speckle tracking; also, image feature tracking using satellite visible-infrared images) (Bindschadler et al., 1994; Joughin, 2002; Rignot et al., 2008; Scambos et al., 1992). The application of InSAR is most accurate but a tracking of long-term ice velocity is not available in fast-moving areas because of unrecoverable unwrapped phases. The intensity correlation of repeat visible-infrared satellite images (e.g. Landsat images) is one of the common methods to measure surface velocity albeit with large time steps. However, it relies on optical surface contrast features that are naturally scarce over ice shelves, and a lack of ground control point on large ice shelves causes large geolocation errors. Both methods are in general limited by data availability, particularly at the highest latitudes of the

\footnotetext{
* Corresponding author at: Getpearl Tower \#503, 12 Gaetbeol-ro, Yeonsu-gu, Incheon, 406-840, Republic of Korea. Tel.: +82 32260 6217; fax: +82322606218.

E-mail address: cklee92@kopri.re.kr (C.-K. Lee).
}

ice shelves. In contrast, ICESat provides improving geolocation accuracy and coverage in these areas, with increasing crossover density up to the satellite latitude limit of $86^{\circ} \mathrm{S}$.

We present a new method to estimate the ice velocity of the large Antarctic ice shelves using the elevation measurements from the Ice Cloud and land Elevation Satellite (ICESat). The Geoscience Laser Altimetry System (GLAS) onboard the ICESat measures elevation with a footprint size of $\sim 65 \mathrm{~m}$ at a space interval of $172 \mathrm{~m}$. Elevation measurement precision is about a decimeter, although under ideal conditions a few centimeters can be achieved (Fricker et al., 2005; Schutz et al., 2005). The accuracy and high resolution of ICESat measurements make it possible to use satellite altimetry as a method of estimating surface velocity on ice shelves.

Abdalati and Krabill (1999) have previously determined ice velocities in portions of the Jakobshavn drainage basin using airborne laser altimetry data. Their technique is based on dense measurements enough to be interpolated onto regularly spaced grids suitable for cross-correlation analysis but densely scanned laser altimetry data are rarely available for large ice shelves. More recently, the correlation between two repeat ICESat tracks have been used to estimate the ice shelf surface velocity (Marsh \& Rack, 2012). However, this method cannot be used as a standalone method as it currently measures only the along-track surface velocity. Instead of these 
correlation analyses, we refine the ice velocity measurement at each crossover location by minimizing the elevation difference of the crossovers re-located in the moving coordinate frame (movement prescribed by the velocity field). Below, we describe this algorithm in detail and then present a revised ice velocity of the Ross Ice Shelf (RIS) for 2003-2009 periods.

\section{Data}

\subsection{ICESat data}

ICESat data products GLA12 (release 531, for ice sheet elevations) operated from October 2003 to April 2009 (15 campaigns) are used in this study. We apply an inverse barometer correction to remove the atmospheric loading using the European Centre for Medium-Range Weather Forecasts' ERA-Interim data (Simmons et al., 2007) along with the saturation correction. Our analysis of various tide models over the RIS finds that the ICESat measurements corrected by the Circum-Antarctic Tidal Simulation model (CATS2008a), an update of Antarctic regional models by Padman et al. (2002) yields an RMS crossover height difference of $\sim 0.17 \mathrm{~m}$, whereas those corrected by the GOT99.2 model, which is already applied to current ICESat data products, yields $\sim 0.27 \mathrm{~m}$. Therefore, we use the CATS2008a to substitute for GOT99.2.

\subsection{Crossovers}

Crossovers are the intersections of ascending and descending ICESat laser profile tracks. We focus particularly on the intercampaign crossovers (crossovers between tracks from two different campaigns) so that a sufficient time has passed between the surface elevation measurements to refine the velocity. Since we use all ICESat profiles acquired in 15 campaigns, a maximum of 210 inter-campaign crossovers are available for a crossover point. The intra-campaign crossovers (crossovers between tracks from a campaign) are used to assess the measurement errors in ICESat elevation profiles because the effects from ice flow are negligible within a campaign (the mean time difference of intra-campaign crossovers is $\sim 11$ days). The crossover measurement density significantly increases toward the ICESat maximum latitude $\left(\sim 86^{\circ} \mathrm{S}\right)$ (Fig. 1$)$. For example, the number of inter-campaign crossovers from 15 ICESat campaigns in an area of $0.5^{\circ}$ (latitude) $\times 2^{\circ}$ (longitude) is $\sim 500$ at the latitude of $78^{\circ} \mathrm{S}$, while it exceeds 2000 at the latitude of $84^{\circ} \mathrm{S}$.

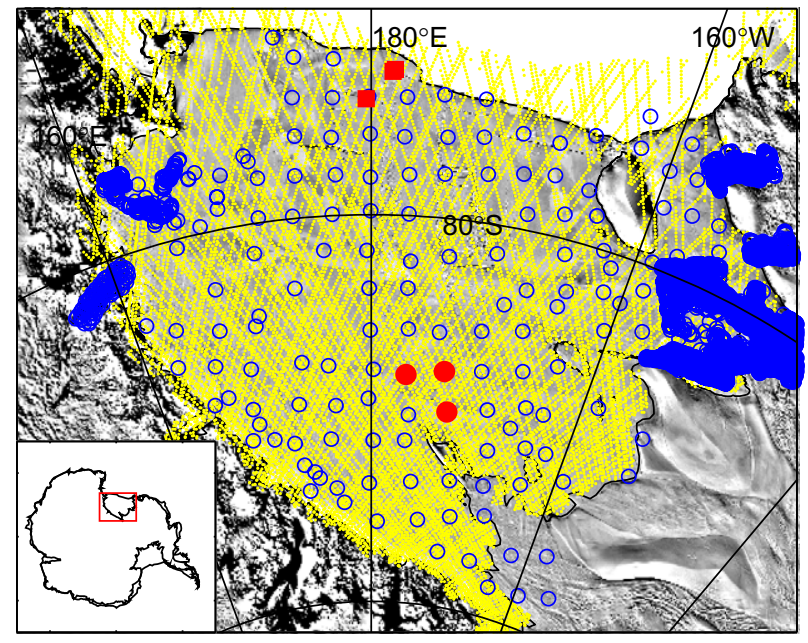

Fig. 1. ICESat tracks of Laser 2a (yellow lines) and velocity observations from the VELMAP (blue circles) used to set the initial velocity in the RIS. The red squares are the GPS stations occupied in 2005 (Brunt, 2008), and the red dots are three RIGGS stations for validation mentioned in Section 4.3.

\subsection{Velocity data for the Ross Ice Shelf}

The Antarctic Ice Velocity Data (VELMAP) distributed by National Snow and Ice Data Center (NSIDC; http://www.nsidc.org/data/velmap) are used as the initial velocity fields. The VELMAP data set in the RIS is a compilation of several sources acquired at several times from 1970s to the 1990s (Fig 1). The Ross Ice Shelf Geophysical and Glaciological Survey (RIGGS) obtained the ice velocity by the point-positioning method from 1972 to 1974 over the entire RIS (Thomas et al., 1984). Along the Siple Coast and downstream of Skelton Glacier, many velocity data were acquired by the correlation method of Landsat images from 1987 to 1990 (Scambos et al., 1992). The velocities of Byrd Glacier were determined by photogrammetric methods from two sets of aerial photographs taken in 1978 and 1979 (Brecher, 1986).

\section{Method}

\subsection{Relocation of ICESat profile into the moving coordinate frame}

Two sections of laser elevation profile at an inter-campaign crossover do not refer to the same location on the ice surface due to flow of the ice sheet. In order to find the crossover area on the moving ice, we relocate the ICESat measurements into a new coordinate system moving with a velocity $\mathbf{v}$. If the origins of the stationary (geodetic) coordinate system and the moving coordinate system coincide at time $t_{0}$ (reference time), the position vector in the moving coordinate systems $\left(\mathbf{r}^{\prime}\right)$ is described under the Galilean transform: $\mathbf{r}^{\prime}=\mathbf{r}-\mathbf{v}\left(t-t_{0}\right)$, where $\mathbf{r}$ is the position vector in the geodetic coordinate system and $t$ is the measurement time. We then find new sets of crossovers displaced from the crossovers in the geodetic coordinate system. Hereafter, we call the conventional crossover in the geodetic coordinate system "orbital crossover" and the new crossover in the moving coordinate system "ice-surface crossover" (Fig. 2). The elevation difference between two shot points at the 'ice-surface' crossover will approach zero if velocity of the moving coordinate frame is valid and elevation changes from other effects (i.e. snow accumulation, basal melting, and spreading) are negligible (Fig. 2).

\subsection{Factors influencing the crossover differences}

The crossover elevation differences of orbital crossovers $(\Delta h)$ contain elevation differences due to ice flow $\left(\Delta h_{\mathrm{f}}\right)$, elevation difference due to ice thickness change $\left(\Delta h_{\mathrm{t}}\right)$, and measurement error $\left(e_{\mathrm{m}}\right)$ : $\Delta h=\Delta h_{\mathrm{f}}+\Delta h_{\mathrm{t}}+e_{\mathrm{m}}$. The elevation differences caused by ice flow $\left(\Delta h_{\mathrm{f}}\right)$ play the key role in our derivation of the velocity fields. Considering the mean ice velocity in the RIS $\left(\sim 500 \mathrm{~m} \mathrm{yr}^{-1}\right)$ and the mean time difference of inter-campaign crossovers $(\sim 2 \mathrm{yr})$, the amount of ice movement inherent in inter-campaign crossovers is $\sim 1 \mathrm{~km}$ in average. The variability of $\Delta h_{\mathrm{f}}$ is thus expected to be about $0.5 \mathrm{~m}$ roughly measured by the standard deviation of elevation differences at $1 \mathrm{~km}$ lag. On the other hand, the ice thickness change $\left(\Delta h_{\mathrm{t}}\right)$ is mainly dependent on the snow accumulation $\left(\Delta h_{\mathrm{a}}\right)$, basal melting $\left(\Delta h_{\mathrm{b}}\right)$, and deformation $\left(\Delta h_{\mathrm{d}}\right)$. Compilations using in situ data and the Advanced Microwave Scanning Radiometer (AMSR-E) show that the accumulation rate ranges between 106 to $147 \mathrm{~kg} \mathrm{~m}^{-2} \mathrm{yr}^{-1}$ in the RIS, which was converted to a firn-equivalent accumulation rate $\left(\Delta h_{\mathrm{a}}\right)$ of 0.30 to $0.42 \mathrm{~m} \mathrm{yr}^{-1}$ using a firn density of $350 \mathrm{~kg} \mathrm{~m}^{-3}$ (Arthern et al., 2006). Glacial melt from the RIS was estimated to be $33-55 \mathrm{~km}^{3} \mathrm{yr}^{-1}$ from the data-based analysis of melt water production (Loose et al., 2009). Applying the area of RIS $\left(\sim 487,000 \mathrm{~km}^{2}\right)$, the basal melt rate $\left(\Delta h_{\mathrm{b}}\right)$ in the overall RIS is about 0.07 to $0.11 \mathrm{~m} \mathrm{yr}^{-1}$. If we assume that the strain rate in the RIS is in the range from 0.0005 to $0.001 \mathrm{yr}^{-1}$ (Alley et al., 2008), the thickness change rate due to ice deformation $\left(\Delta h_{\mathrm{d}}\right)$ is approximately -0.8 to $-0.15 \mathrm{~m} \mathrm{yr}^{-1}$ using the strain rate correction, which is defined as the product of strain rate and ice thickness. Combining all three effects $\left(\Delta h_{\mathrm{a}}-\Delta h_{\mathrm{b}}+\Delta h_{\mathrm{d}}\right)$, the total thickness 

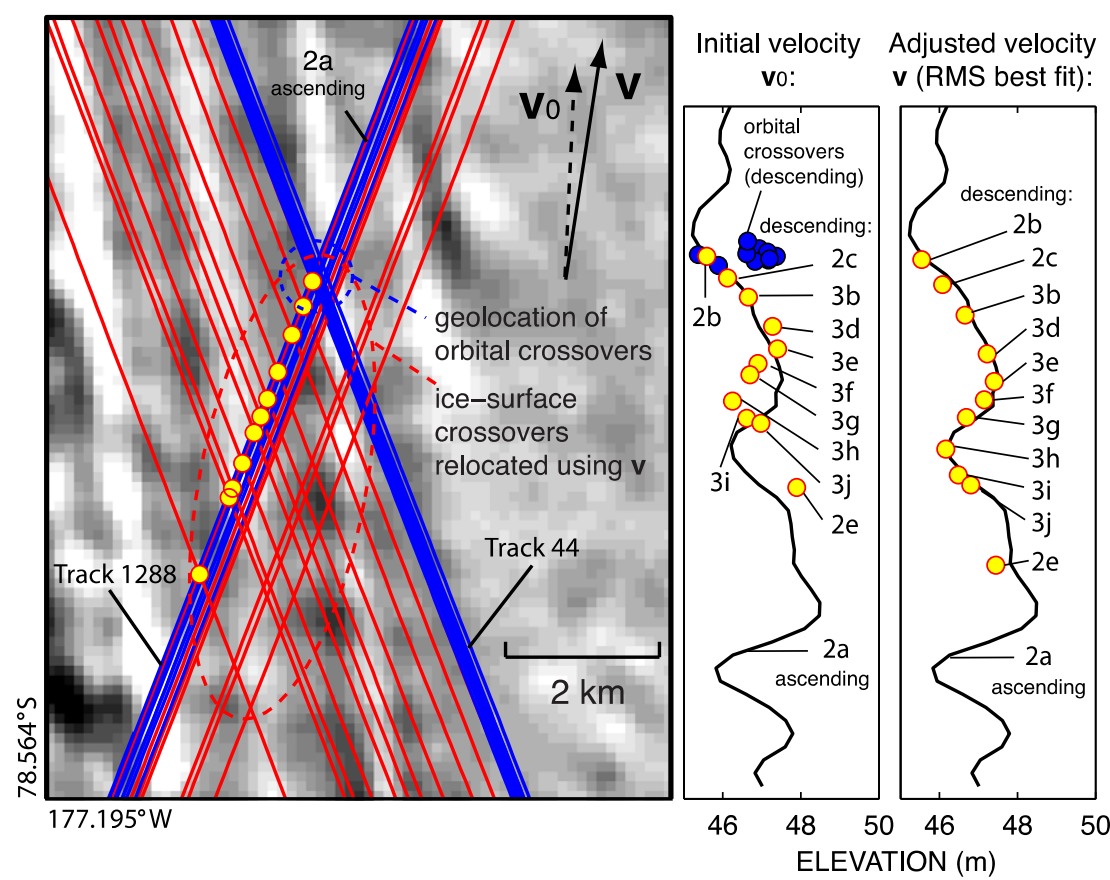

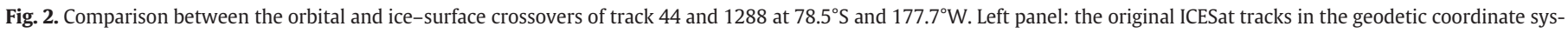

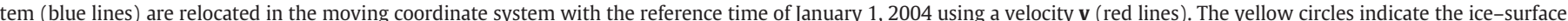

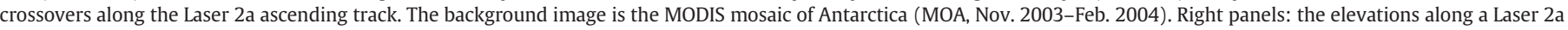

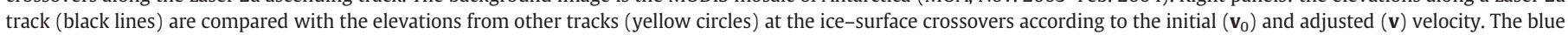
circles indicate the elevations at the orbital crossovers.

change rate varies in the range from -0.6 to $0.2 \mathrm{~m} \mathrm{yr}^{-1}$. Since the elevation change is about 0.11 times the thickness change of ice in sea water, the $\Delta h_{\mathrm{t}}$ during the mean time difference of inter-campaign crossovers $(\sim 2 \mathrm{yr})$ is in the range from -0.14 to $0.04 \mathrm{~m}$ taking up a portion much smaller than the effect of ice flow $(\sim 0.5 \mathrm{~m})$.

The measurement error $\left(e_{\mathrm{m}}\right)$, which includes the errors in the sensor, atmospheric and tide correction, wind transport of surface snow, crossover interpolation, etc., can be assessed by the elevation difference of the intra-campaign crossover (crossover between two tracks from a campaign) because the effects from ice flow and ice thickness change are negligible within a campaign (the mean time difference of intracampaign crossovers is $\sim 11$ days). The RMS elevation difference of intra-campaign crossovers is $\sim 0.17 \mathrm{~m}$ over the RIS. The geolocation error of the ICESat tracks result in some error in the velocity estimation, but these are small relative to the ice movement ( $1 \mathrm{arcsec}$, or $\sim 3.5 \mathrm{~m}$ ) (Luthcke et al., 2005). Consequently, since the ice flow is the most important factor influencing the crossover elevation difference and the measurement error is random, we expect a reasonable estimate of the ice velocity by means of searching on the velocity of the moving coordinate frame, seeking to minimize the elevation differences of ice-surface crossovers (to a limit approaching $\sim 0.17 \mathrm{~m}$ on average over the shelf).

\subsection{Velocity refinement by minimizing the crossover difference}

We apply the RMS elevation difference of ice-surface crossovers to the fitting function $(f)$ in the minimization formula, expressed as

$\min _{\mathbf{v}}=\min _{\mathbf{v}} \sqrt{\sum_{i}\left[h_{\mathrm{a}}^{\prime}\left(\mathbf{r}_{i}^{\prime}\right)-h_{\mathrm{d}}^{\prime}\left(\mathbf{r}_{i}^{\prime}\right)\right]^{2}}$

where $h_{\mathrm{a}}^{\prime}\left(\mathbf{r}_{i}^{\prime}\right)$ and $h_{\mathrm{d}}^{\prime}\left(\mathbf{r}_{i}^{\prime}\right)$ are the elevations measured along ascending and descending profiles at the position of the $i$ th ice-surface crossover $\left(\mathbf{r}_{i}^{\prime}\right)$ respectively.

We first examined the behavior of our fitting function in a test area (Fig. 3). The fitting functions were exhaustively calculated in a pre- defined velocity space with a maximum deviation of $200 \mathrm{~m} \mathrm{yr}^{-1}$ from a given initial velocity and an interval of $10 \mathrm{~m} \mathrm{yr}^{-1}$ (Fig. 3b). The velocity deviation from the initial velocity can be determined by finding the position of minimal fitting function $\left(100 \mathrm{~m} \mathrm{yr}^{-1}\right.$ in an eastward direction and $10 \mathrm{~m} \mathrm{yr}^{-1}$ in a northward direction in this example). Fig. 3c and Fig. 3d compare the elevations along the ICESat tracks relocated into the moving coordinate systems with the initial velocity and the velocity estimated from the minimal fitting function, respectively, and superimposed on a MODIS composite mosaic of Antarctica (MOA, Nov. 2003-Feb. 2004) (Scambos et al., 2007). Looking into three black circles, the features in the ICESat tracks relocated with the estimated velocity are remarkably well aligned with the linear features in the MODIS mosaic, indicating the improvement of ice velocity.

The quadratic shape and unique minimum of fitting function indicate that the solution can be efficiently found by the non-linear least square inversion. We use the trust-region non-linear least square method with two unknown parameters (horizontal velocity $v_{x}$ and $v_{y}$ ) in order to minimize the fitting function. The trust-region method is a kind of iterative methods for optimization, which is robust and can be applied to ill-conditioned problems, similar to the classical Levenberg-Marquardt method. In the trust-region algorithm for non-linear least squares, the approximate model such as quadratic approximation is only trusted in a region near the current iterate so that the update of solution is bounded in the "trust region" updated from iteration to iteration (Moré \& Sorensen, 1983).

\section{Result}

\subsection{Velocity adjustment over the RIS}

To increase the signal to noise ratio, the area patch, from which velocity is determined, must contain a sufficient number of crossovers. We use circular patches with radii corresponding to $1^{\circ}$ in longitude. The patches are located in a regularly spaced grid within the ice shelf with intervals of $0.125^{\circ}$ in latitude and $0.5^{\circ}$ in longitude 

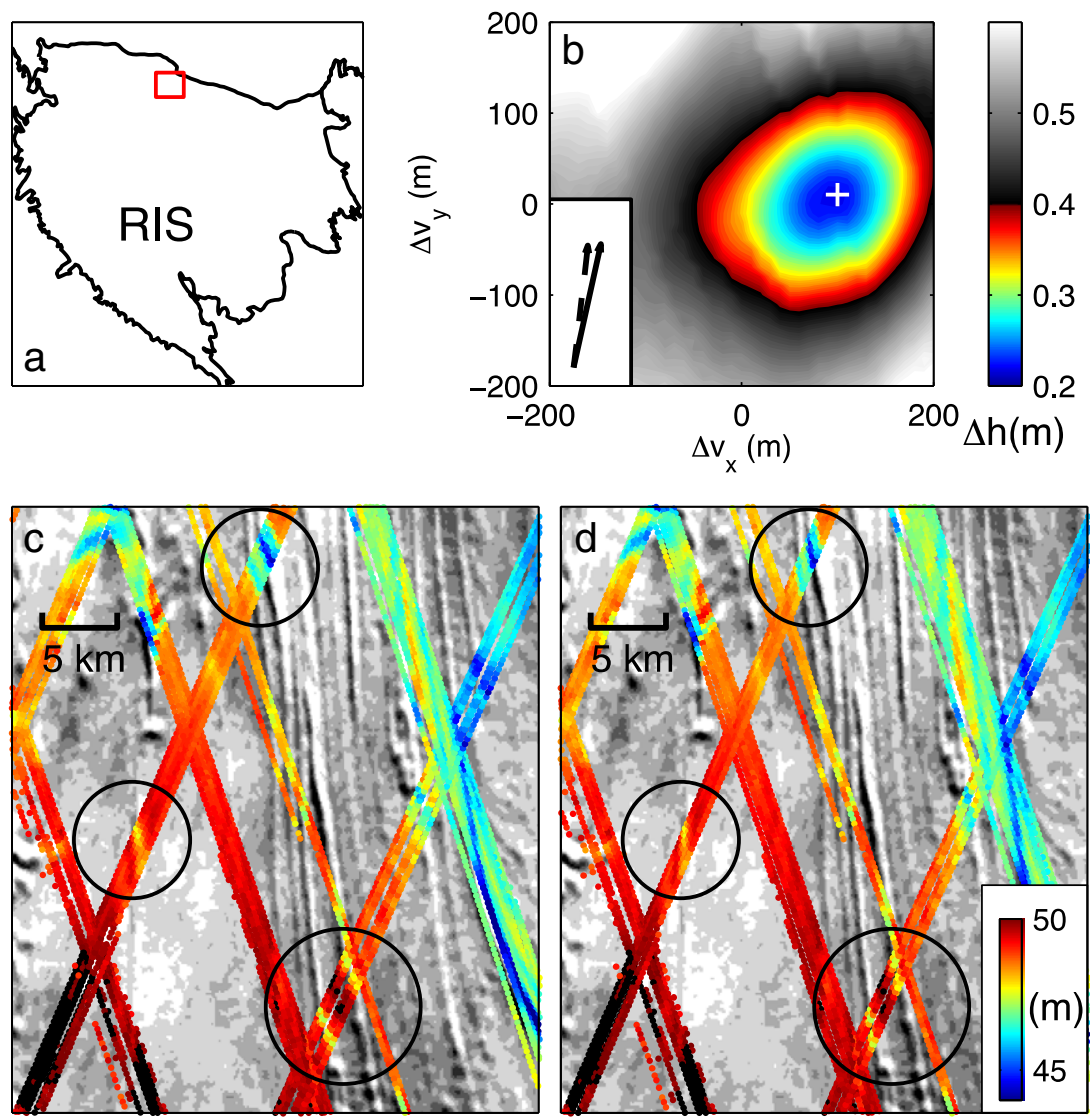

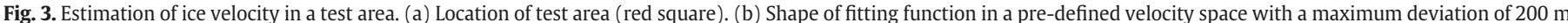

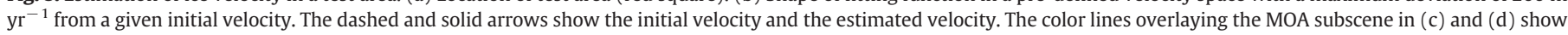
surface undulations along the ICESat tracks after relocating with (c) the initial velocity and (d) the estimated velocity.

over the RIS (3989 assessment patches, roughly $15 \mathrm{~km}$ in diameter at the latitude of $82^{\circ} \mathrm{S}, \sim 380$ crossovers per patch in average). The initial velocity fields are linearly interpolated and extrapolated from the VELMAP velocity as described in Section 2.3. Fig. 4 shows the new ice velocity field over the RIS compared with the initial velocity field. The mean value of the deviation from initial velocity is about $-48 \mathrm{~m} \mathrm{yr}^{-1}$. The largest differences between initial and new velocity are observed on the northwestern and southernmost part of the ice shelf and the ice front near Roosevelt Island. In the northwestern part, our velocity estimation correctly adjusts the initial velocity distribution that contains artifacts due to the data gap in VELMAP (Fig.1). Negative velocity differences over a large area on the southernmost part indicate the recent slowdown of the Siple Coast ice streams A and B (now Mercer and Whillans ice streams) (Bindschadler \& Vornberger, 1998; Joughin et al., 2002). The positive velocity difference along the ice front near the Roosevelt Island results from the velocity discontinuity across a large rift growing after the calving of B15 iceberg in March 2000 (Joughin \& MacAyeal, 2005).

\subsection{Uncertainty analysis}

The RMS elevation difference of the crossovers at the velocity estimates $\hat{v}$ indicates the uncertainty of our scheme, since the ultimate goal of the velocity inversion is to minimize the RMS crossover difference to the measurement error level. Fig. 5 shows the histogram of RMS elevation differences from the 3989 area patches over the RIS. The RMS elevation differences of the crossovers at $v=\hat{v}$ are significantly smaller than those of the crossovers at $\mathbf{v}=0$ (orbital crossovers) and $\mathbf{v}=\mathbf{v}^{0}$, representing the improvement of velocity.
However, the peak of histogram at $v=\hat{v}(\sim 0.17 \mathrm{~m})$ is greater than the peak of measurement error $(\sim 0.13 \mathrm{~m})$. We can thus expect that the residual error except for the measurement error is $\sim 0.11 \mathrm{~m}$ ( $=\sqrt{\left.(0.17)^{2}-(0.13)^{2}\right)}$. This residual error results from effects ignored in our algorithm, i.e., the elevation changes due to the ice thickness change, the velocity variation within a patch (or, equivalently, strain of the ice within the patch), and non-linear time variations of velocity.

The formal error of our velocity estimates can be derived from the covariance of model parameters, $\operatorname{cov}(\mathbf{v})=\sigma_{\mathrm{d}}^{2}\left(\mathbf{A}^{T} \mathbf{A}\right)^{-1}$, where Ais the Jacobian at the final solution and $\sigma_{\mathrm{d}}^{2}$ is the data variance (Menke, 1989). If the RMS crossover difference of the crossovers at the velocity estimates is applied to the data variance $\sigma_{\mathrm{d}}^{2}$ in each patch, the formal errors in average are $4.1 \mathrm{~m} \mathrm{yr}^{-1}$ and $6.6 \mathrm{~m} \mathrm{yr}^{-1}$ for the eastward and northward components respectively. Fig. 6 shows the distribution of formal error. The formal errors of northward velocity component are $\sim 60 \%$ larger than those of eastward ones because the linear features on the ice surface are aligned along the northward direction dominantly. Large formal errors along the ice front probably result from the rapid basal melts and calving processes. The extremely smooth ice surface (e.g. a flat plain) also decreases the signal to noise ratio (hence increases the uncertainty of velocity estimates), as observed as the pattern with relatively large formal errors aligned along the flow direction. Even though the measurements on the grounded ice were removed using the grounded ice mask in the CATS2008a model, the formal errors are large in some areas near the grounding line because of inaccurate grounded ice mask and large errors in the tide model. On the other hand, the random noises observed in the difference between the initial and estimated 


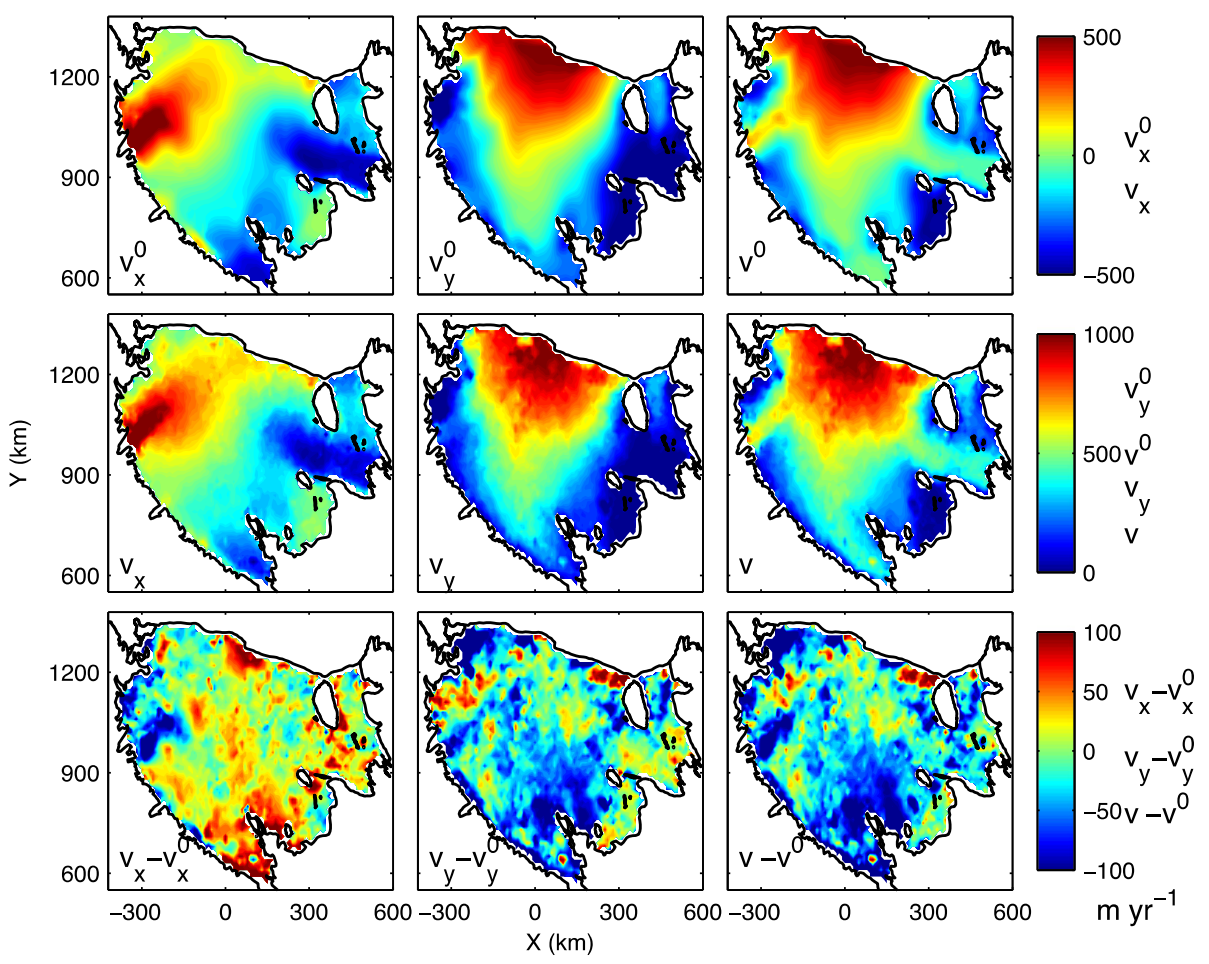

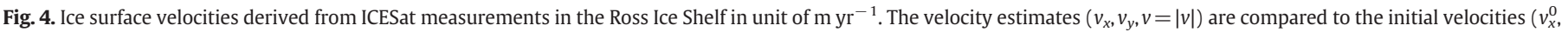
$\left.v_{y}^{0}, v^{0}=\left|v^{0}\right|\right)$.

velocities in Fig. 4 are a little larger than the formal error estimates. This means that the actual errors in velocity estimates are slightly larger than the formal errors.

\subsection{Validation of velocity estimates}

There are few in situ velocity measurements on the RIS during the ICESat campaign period (2003-2009). We compared our results with GPS measurements acquired near the ice front in 2005 (Brunt, 2008) and InSAR velocity estimates from the Antarctic Mapping Mission (AMM-1) in 1997 and the Modified Antarctic Mapping Mission (MAMM) in 2000 (Jezek, 2002). Fig. 7a shows the velocity vectors at three GPS stations (R13, NASS, and NASC). The velocity vectors from the GPS and InSAR measurements are somewhat eastward of the initial velocity (from the RIGGS). The directions of the velocity

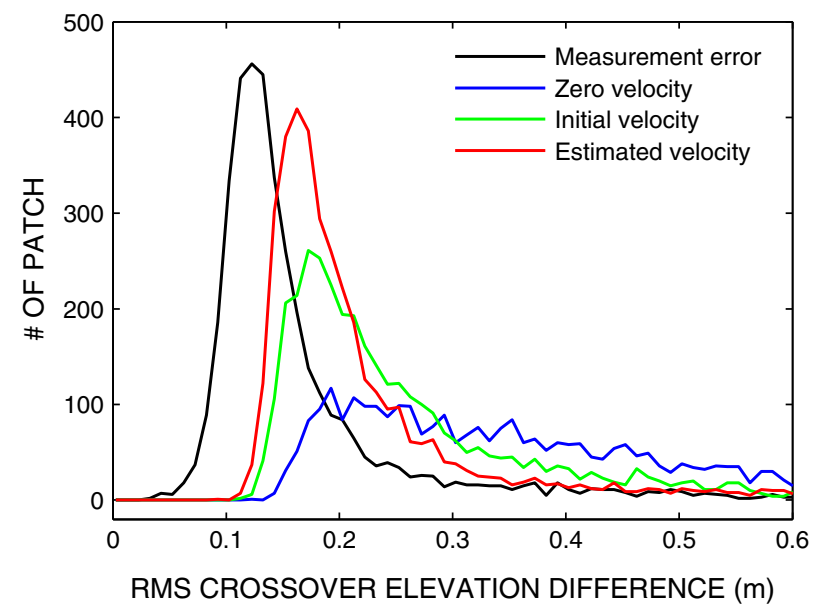

Fig. 5. Histograms of RMS crossover elevation differences for intra-campaign crossovers (measurement error), crossovers at zero velocity, crossovers at the initial velocity, and crossovers at the estimated velocity. vectors obtained in this study are close to those of the GPS and InSAR measurements at the NASS and NASC stations. Fig. 7b presents the velocity estimates at the three RIGGS stations (J10, K10, and K11) downstream of Crary Ice Rise, where Joughin et al. (2002) document a slowdown of $\sim 69 \mathrm{~m} \mathrm{yr}^{-1}$ from 1974 to 1997 based on the velocities from RIGGS and InSAR. Our velocity estimates are similar to those from InSAR but indicate a slowdown of $\sim 80 \mathrm{~m} \mathrm{yr}^{-1}$ from 1974 to 2006.

\section{Discussion}

The velocity estimation from ICESat measurements works well on ice shelf surfaces with characteristic topographic features. However, under the conditions of extremely smooth ice, ice with rapidly changing surface features, or ice with only linear features aligned exactly along flow direction, the velocity adjustment we describe would fail. If the initial velocity differs too much from the true velocity during the laser measurement period, the minimization of fitting function by our non-linear least squares method could converge to an erroneous local minimum, resulting in false velocities. Our assumption that regional ice thickness changes can be ignored fails in areas where large and rapid basal melting occurs (e.g. along the ice front). The melt rate in the front of RIS is as high as $2.8 \pm 1.0 \mathrm{~m} \mathrm{yr}^{-1}$ (surface elevation change of $0.31 \pm 0.1 \mathrm{~m} \mathrm{yr}^{-1}$ ) and exponentially decreased with the distance from the ice front (Horgan et al., 2011). According to their estimates, the surface elevation change due to basal melt is able to exceed $0.1 \mathrm{~m} \mathrm{yr}^{-1}$ within the front $20 \mathrm{~km}$. To obtain more accurate velocity in the area with rapid basal melting, the effect of ice thickness change should be removed by an additional parameterization (e.g. linear trend fitting) in the inversion. In addition, significant deformation due to strain within an assessment patch would violate our uniform velocity assumption within patch, and would lead much higher residual errors for the fits.

The limitations of our method cause a few outliers in the velocity estimates as shown in the velocity difference map of Fig. 4 . We remove the velocity estimates with the formal errors larger than $13 \mathrm{~m}$ 

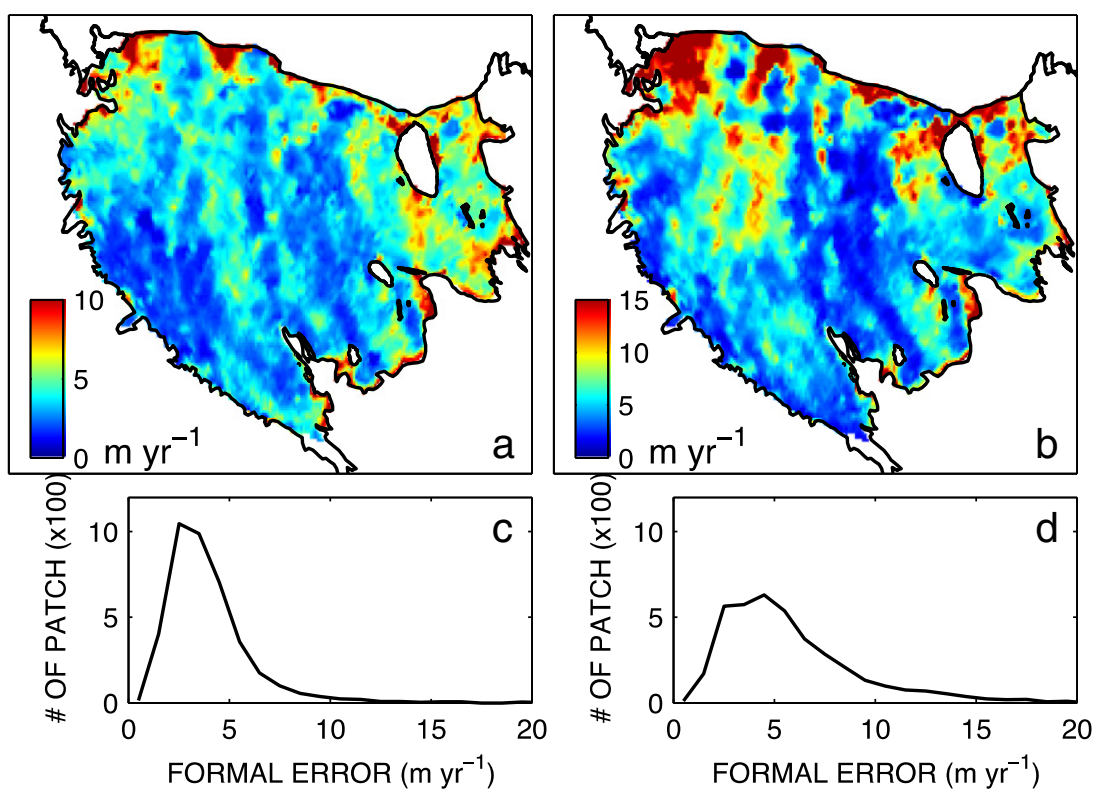

Fig. 6. Formal error of the velocity estimated from ICESat measurements: distribution of (a) eastward and (b) northward velocity estimates and their histograms (c, d).

$\mathrm{yr}^{-1}$ and then apply $3 \times 3$ median filter to generate the final product of velocity map (Fig. 8a). The velocity differences at the RIGGS stations provide information for the dynamical evolution of RIS during last three decades (Fig. 8b). The deceleration of Whillans Ice Stream is affecting the velocity structure in the ice shelf far away $(>300 \mathrm{~km})$ from the grounding lines. In the area enclosed by the white line in Fig. 8b, the slowdown is $98 \pm 34 \mathrm{~m} \mathrm{yr}^{-1}(\sim 23 \%)$ and the deceleration rate is $3.1 \pm 1.1 \mathrm{~m} \mathrm{yr}^{-2}$. These values are reasonable though they are slightly lower than earlier estimates of deceleration on Whillans Ice Stream (Bindschadler \& Vornberger, 1998; Joughin et al., 2002). For instance, our estimates of deceleration ( $2.5 \mathrm{~m}$ $\mathrm{yr}^{-2}$ from 1974 to 2006) at J10, K10, and K11 RIGGS stations (shown in Section 4.3) are lower than the earlier deceleration rate ( $3.0 \mathrm{~m} \mathrm{yr}^{-2}$ from 1974 to 1997) from Joughin et al. (2002). However, the recent decrease of deceleration rate cannot be assured because there exists the uncertainty of deceleration rate $\left(> \pm 0.5 \mathrm{~m} \mathrm{yr}^{-2}\right)$ due to the velocity estimate errors $\left(\sigma_{\text {RIGGS }}=\sim 15 \mathrm{~m} \mathrm{yr}^{-1}, \sigma_{\text {ICESat }}=\sim 8 \mathrm{~m}\right.$ $\mathrm{yr}^{-1}$, and $\sigma_{\text {InSAR }}=\sim 2 \mathrm{~m} \mathrm{yr}^{-1}$ at J10, K10, and K11 RIGGS stations).

The upcoming polar laser altimeter mission, ICESat-2, will be a continuously-operating, photon-counting mission in the 91-day repeat pattern (Abdalati et al., 2010). The main sensor, the Advanced Topographic Laser Altimeter System (ATLAS), will have 6 beams, arranged in three pairs, each pair separated by $90 \mathrm{~m}$, with pairs spaced $3 \mathrm{~km}$ apart. With pointing knowledge of around $10 \mathrm{~m}$ and repeattrack pointing accuracy of a few tens of meters, ICESat-2 will in effect provide three swaths of elevation plus absolute slope knowledge, with a vertical accuracy of 5 to $10 \mathrm{~cm}$. Applying our technique to ICESat-2 data, assuming an excellent tide correction, could yield a detailed velocity mapping up to 4 times per year, or, after approximately 2 yrs, a detailed velocity change map with similar accuracy to the 6year map we have derived from ICESat data here. Moreover, the continuous operation in the 91-day repeat pattern, and the three beam-
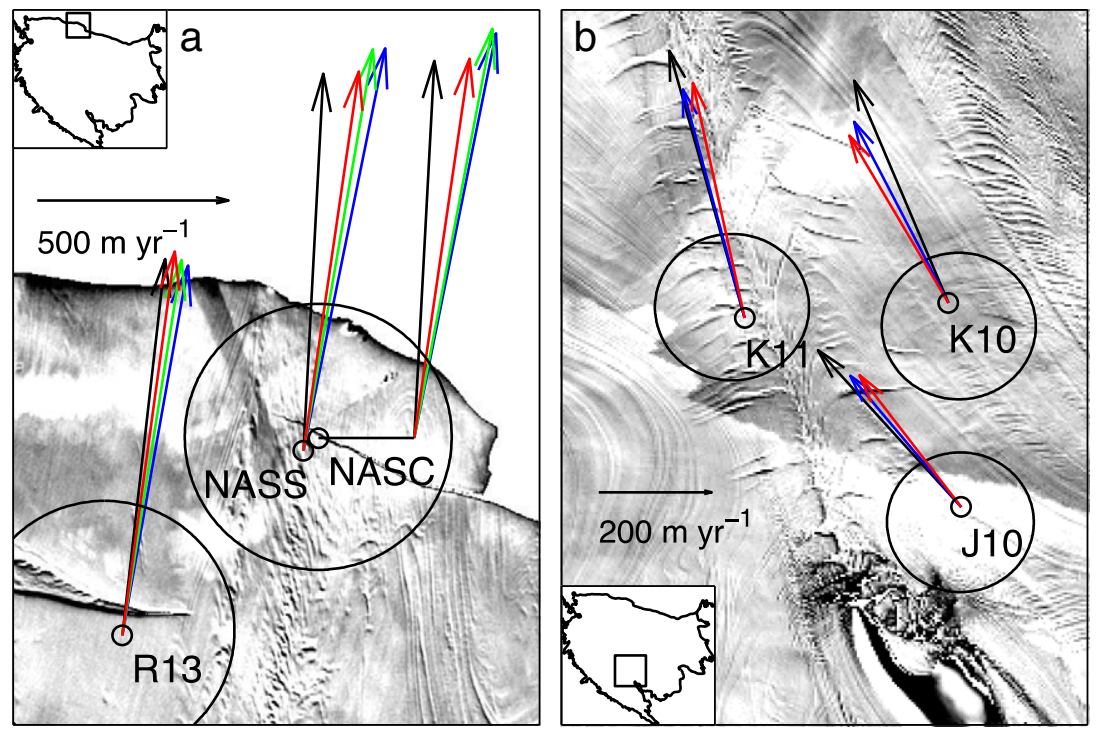

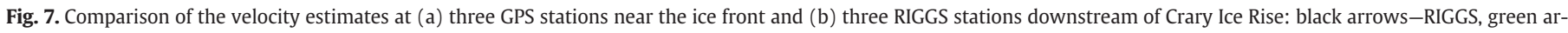

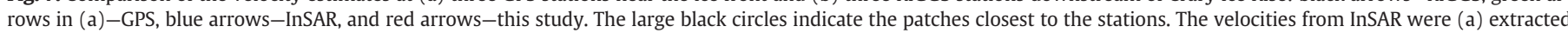

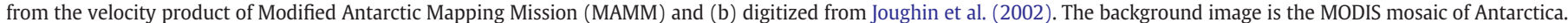




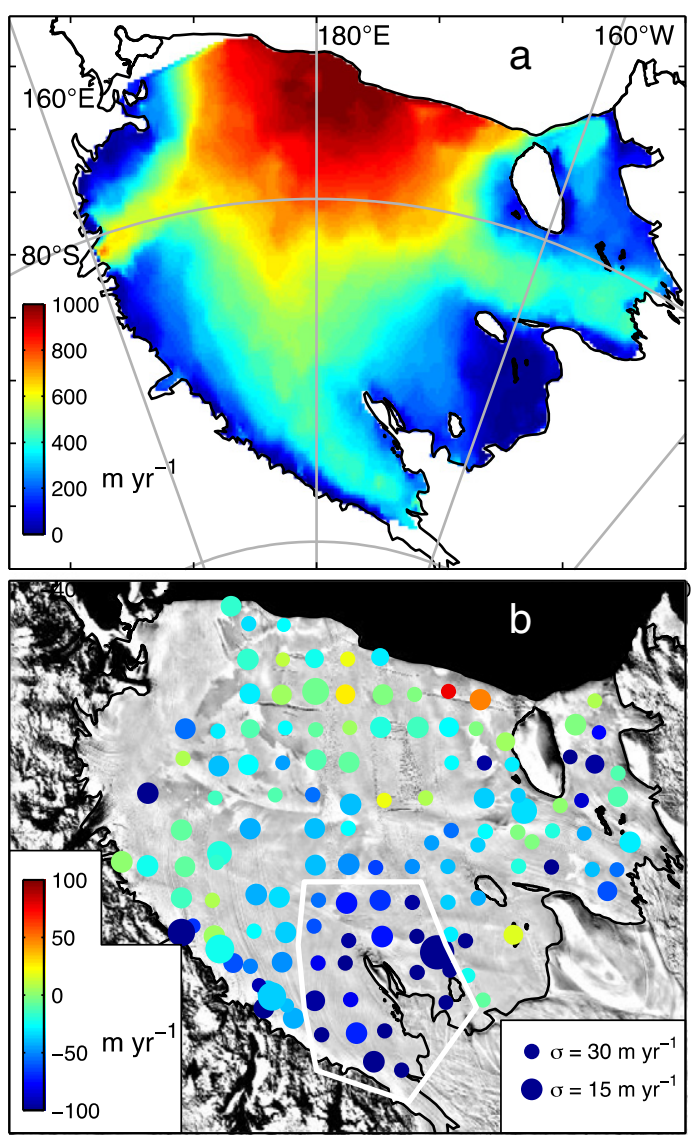

Fig. 8. (a) Ice velocity in the RIS after removing the patches with large formal errors $\left(\sigma_{\text {ICESat }}>13 \mathrm{~m} \mathrm{yr}^{-1}\right)$ and applying the $3 \times 3$ median filter and $(\mathrm{b})$ the velocity difference between RIGGS measurements and ICESat estimates. The color of dot in (b) indicates the velocity difference and the size of dot indicates the combined error $\left(=\sqrt{\sigma_{\text {ICESat }}^{2}+\sigma_{\text {RIGGS }}^{2}}\right)$ contained in the velocity difference. The white line encloses the area where large slowdowns are observed.

pair configuration, will yield $\sim 54$ times the number of crossover regions (i.e. velocity measurement points). A further improvement in an ICESat-2-based application of our technique comes from the availability of both slope and elevation data continuously along the beam-pair swaths. This in effect provides two parameters for the RMS fitting routine to optimize, improving accuracy, and leading to maps of changing deviatoric strain as well as changing velocity over time.

\section{Conclusion}

The ice velocity mapping on ice shelves using the high-accuracy and high-resolution laser altimetry can be an alternative scheme to investigate the dynamical evolutions of large-scale ice shelves. The velocity adjustment minimizing the elevation difference of the crossovers attached on the ice shelf surface achieves accurate velocity estimates in the presence of surface (topographic) undulations but in the absence of time-varying thickness changes or surface deformations. Although the inferred errors of velocity estimates are larger than those of InSAR application, there are still some advantages. The altimetric approach can provide a long-term averaged velocity with low costs of computation and data storage whereas the InSAR uses relatively short repeats (up to tens of days). Accurate geolocation of ICESat data facilitates estimating the absolute motion of ice so that the absolute calibration of velocity data, which is a challenging issue in the InSAR velocity mapping in Antarctica, is not necessary.
To overcome the limitation of our method (discussed in Section 5), further improvements must be studied, i.e., including the vertical velocity (elevation change rate) and regional strain rates into the algorithm as additional parameters to be estimated simultaneously. Another potential improvement would be to use patches adaptive to glacier boundaries and rifts. It is also recommended that observations from more sophisticated satellite altimetry missions like namely CryoSat-2 and ICESat- 2 are applied to our technique or jointly processed.

The method suggested in this study would work well on the Ronne-Filchner Ice Shelf as well as the Ross Ice Shelf but would have limited success on small ice shelves or the ice shelves at lower latitudes (e.g. Amery, Fimbul, Getz, or Larsen C) because of low crossover densities. An extension of our scheme to the simultaneous mapping of velocity and vertical elevation change is more important for the Ronne-Filchner, Amery or Larsen C ice shelf, because of their active basal freeze/melt processes.

\section{Acknowledgements}

The authors thank the Byrd Polar Research Center in Columbus, Ohio, for providing the InSAR velocity products and L. Padman for providing the CATS2008a ocean tide model. This work was supported by Korea Polar Research Institute (KOPRI) projects (PE12050). SCH was supported by NASA's Earth Surface and Interior program. TAS was supported by NSF-OPP grant ANT0732919.

\section{References}

Abdalati, W., \& Krabill, W. B. (1999). Calculation of ice velocity in the Jakobshavn Isbrae area using airborne laser altimetry. Remote Sensing of Environment, 67, 194-204.

Abdalati, W., Zwally, H. J., Bindschadler, R., Csatho, B., Farrell, S. L., Fricker, H., et al. (2010). The ICESat-2 laser altimetry mission. Proceedings of the IEEE, 98(5), 735-751.

Alley, R. B., Horgan, H. J., Joughin, I., Cuffey, K. M., Dupont, T. K., Parizek, B. R., et al. (2008). A simple law for ice shelf calving. Science, 322, 1344.

Arthern, R. J., Winebrenner, D. P., \& Vaughan, D. G. (2006). Antarctic snow accumulation mapped using polarization of 4.3-cm wavelength microwave emission. Journal of Geophysical Research, 111, D06107. http://dx.doi.org/10.1029/2004JD005667.

Bindschadler, R., Fahnestock, M. A., Skvarca, P., \& Scambos, T. (1994). Surface-velocity field of the northern Larsen Ice Shelf, Antarctica. Annals of Glaciology, 20(1), 319-326.

Bindschadler, R., \& Vornberger, P. (1998). Changes in the West Antarctic Ice Sheet since 1963 from declassified satellite photography. Science, 279, 689-692.

Brecher, H. H. (1986). Surface velocity determination on large polar glaciers by aerial photogrammetry. Annals of Glaciology, 8, 22-26.

Brunt, K.M. (2008). Tidal motion of the Ross Ice Shelf and its interaction with the Siple Coast ice streams, Antarctica. (Ph. D. thesis). Chicago: University of Chicago.

Fricker, H. A., Borsa, A., Minster, B., Carabajal, C., Quinn, K., \& Bills, B. (2005). Assessment of ICESat performance at salar de Uyuni, Bolivia. Geophysical Research Letters, 32, L21S06. http://dx.doi.org/10.1029/2005GL023423.

Horgan, H. J., Walker, R. T., Anandakrishnan, S., \& Alley, R. B. (2011). Surface elevation changes at the front of the Ross Ice Shelf: Implications for basal melting. Journal of Geophysical Research, 116, C02005. http://dx.doi.org/10.1029/2010JC006192.

Jezek, K. C. (2002). RADARSAT-1 Antarctic Mapping Project: Change-detection and surface velocity campaign. Annals of Glaciology, 34, 263-268.

Joughin, I. (2002). Ice-sheet velocity mapping: A combined interferometric and speckle-tracking approach. Annals of Glaciology, 34, 195-201.

Joughin, I., \& MacAyeal, D. R. (2005). Calving of large tabular icebergs from ice shelf rift systems. Geophysical Research Letters, 32, L02501. http://dx.doi.org/10.1029/ 2004 GL020978.

Joughin, I., Tulaczyk, S., Bindschadler, R., \& Price, S. F. (2002). Changes in west Antarctic ice stream velocities: Observation and analysis. Journal of Geophysical Research, 107(N11), 2289. http://dx.doi.org/10.1029/2001JB001029.

Loose, B., Schlosser, P., Smethie, W. M., \& Jacobs, S. (2009). An optimized estimate of glacial melt from the Ross Ice Shelf using noble gases, stable isotopes, and CFC transient tracers. Journal of Geophysical Research, 114, C08007. http://dx.doi.org/10.1029/ 2008JC005048.

Luthcke, S. B., Rowlands, D. D., Williams, T. A., \& Sirota, M. (2005). Reduction of ICESat systematic geolocation errors and the impact on ice sheet elevation change detection. Geophysical Research Letters, 32, L21S05. http://dx.doi.org/10.1029/2005GL023689.

Marsh, O. J., \& Rack, W. (2012). A method of calculating ice-shelf surface velocity using ICESat altimetry. Polar Record, 48(244), 25-30.

Menke, W. (1989). Geophysical data analysis: Discrete inverse theory. San Diego, Calif.: Academic.

Moré, J. J., \& Sorensen, D. C. (1983). Computing a trust region step. SIAM Journal on Scientific and Statistical Computing, 3, 553-572. 
Padman, L., Fricker, H. A., Coleman, R., Howard, S., \& Erofeeva, L. (2002). A new tide model for the Antarctic ice shelves and seas. Annals of Glaciology, 34, 247-254.

Rignot, E., Bamber, J. L., Van den broeke, M. R., Davis, C., Li, Y., Van de berg, W. J., \& Van Meijgaard, E. (2008). Recent Antarctic ice mass loss from radar interferometry and regional climate modeling. Nature Geoscience, 1, 106-110.

Scambos, T. A., Dutkiewicz, M. J., Wilzon, J. C., \& Binschadler, R. A. (1992). Application of image cross-correlation to the measurement of glacier velocity using satellite image data. Remote Sensing of Environment, 42, 177-186.

Scambos, T. A., Haran, T., Fahnestock, M., Painter, T., \& Bohlander, J. (2007). MODIS-based Mosaic of Antarctica (MOA) data sets: Continent-wide surface morphology and snow grain size. Remote Sensing of Environment, 111(2-3), 242-257. http://dx.doi.org/10.1016/j.rse/2006/12020.
Schutz, B. E., Zwally, H. J., Shuman, C. A., Hancock, D., \& DiMarzio, J. P. (2005). Overview of the ICESat mission. Geophysical Research Letters, 32, L21S01. http: //dx.doi.org/10.1029/2005GL024009.

Simmons, A., Uppala, S., Dee, D., \& Kobayashi, S. (2007). ERA-Interim: New ECMWF reanalysis products from 1989 onwards. ECMWF Newsletter, 110, 25-35.

Thomas, R. H., MacAyeal, D. R., Eilers, D. H., \& Gaylord, D. R. (1984). Glaciological studies on the Ross Ice Shelf, Antarctica, 1972-1978. The Ross Ice Shelf: Glaciology and Geophysics Antarctic Research Series, 42, 21-53. 